\title{
The Assimilation of Social Media in Marketing Management: A Case Review of Taliah's Strategy
}

\author{
Nelson Obinna Omenugha \\ Correspondence: Nelson Obinna Omenugha, Doctorate Scholar and Teaching Assistant, School of Films and TV Arts, \\ Xi' an Jiaotong-Liverpool University, Suzhou, China.
}

Received: August 1, 2018

Accepted: August 27, 2018

Online Published: August 28, 2018

doi:10.11114/bms.v4i3.3573

URL: https://doi.org/10.11114/bms.v4i3.3573

\begin{abstract}
Aim: To review and discuss the use of social media platforms as digital marketing tool and promotional strategy by brands. The digital age inevitably brings changes and increased competition in ways businesses target, reach and recruit customers. This phenomena raises the question of which medium or media do businesses adopt in the marketing effort to reach, inform and convert customers; ultimately for survival? This review is an attempt to address this question within the context of the promotional activities of a beauty brand, Taliah.
\end{abstract}

Approach: A review was conducted on the social media marketing activities of Taliah. It discusses different social media platforms such as Facebook, Twitter, Instagram and YouTube which the brand has combined to target, reach, persuade and convert their customers. In addition, the review identified four factors that reasonably affect the social media marketing as time and date; personality, call to action and post type. Consequently, this logical approach towards the subject-matter would help to provide knowledge and facilitate reaching the best-fit decision that can optimize the marketing activities of brands and businesses; considering the increasingly evolving technological era.

Findings: The review considers the evolving changes in business as a result of the presence of various digital and interactive platforms and technologies. The study recognizes that the social media platforms provide opportunities for media content; including information on products and services to be processed and distributed to the targets. There is a worry that the market space is increasingly becoming competitive; particularly as consumers are empowered by the digital technologies to make informed choices among different brands and businesses. Arguably, this is one of the major factors that triggered the competition in the market and among brands.

Review limitations/implications: The characteristics of the impact of the social media marketing on brands and businesses have recently been widely discussed because of their general applicability. Consequently, it is impossible to review and cover all the important aspects of the subject-matter in this review. This review focuses on the Taliah brand and how it has particularly conducted its social media and digital marketing management. It also examines four factors that reasonably affect the social media marketing; namely, time and date; personality, call to action and post type. The review examines and provides its own views based on content analysis of the social media marketing activities of Taliah brand.

Practical implications: The review highlights the activities, benefits and challenges of applying social media as a marketing and promotional strategy. Social media platforms provide the channel through which brands and businesses can develop and disseminate information about their activities to their targets in an easy, less expensive and convenient manner. On the other hand, if brands and business understand the factors affecting the social media marketing; namely, time and date; personality, call to action and post type - they would be better prepared to checkmate these factors; including been able to aptly adapt the strengths of the social media in their marketing activities. This complement would strike the balance and potentially present a practical means through which brands could coordinate their marketing efforts in using various social media platforms. It is also crucial to gain insight into other factors that potentially impacting the activities of social media marketing strategy.

Value: The review considers that the increasing changes in the market is itself an opportunity for the brands to rethink strategy on how various digital technologies and networking platforms can be optimized in marketing their activities and information. It is crucial and beneficial to emerging businesses and academics to understand how Taliah brand 
combined and utilized diverse social media platforms to target, reach out and recruit target customers; ultimately boosting its market shares.

Keywords: social media, digital marketing, brand management, promotional strategy, Taliah, customer satisfaction.

\section{Introduction}

The social media platform has been recognized by brands and businesses as a strategic tool for marketing and promotion of ideas and activities. In addition to providing for the optimization of content, social media presents a platform for the origination of content that helps engage and build social connections with users. This paper is an overview content case review of the social media marketing activities of Taliah beauty brand. The brand had utilized diverse social media platforms in digital marketing and promotion of its value and activities. Particularly, this review examines the nature of social media platform and the potentials that enable Taliah beauty brand to adopt and manage them as a digital marketing and promotional tool towards attaining its goal. Like every business, Taliah aims to reach, engage, educate, recruit and retain its target customers. In the face of a competitive and evolving market, this case review offers a real-time practical insight on how Taliah had utilized and managed different social media platform to build a market niche and enhance its brand positioning in the Beauty industry. Situated within social network theory, the generated insights would offer strategies and guide emerging businesses on how the social media platform could be used to optimize brand performance in a competitive market. Moreover, social media strategy research is of relevance to the practitioners and provides knowledge for further academic inquiries.

\subsection{Understanding Digital Marketing}

Digital marketing involves all activities aimed at communicating the values of goods and services via internet-enabled platforms in order to meet corporate objectives of attracting, recruiting and satisfying customer needs (Jobber and Ellis-Chadwick, 2013; Kaplan \& Haenlein, 2010; Korper \& Ellis 2001). It is an online effort to disseminate information on products and services to target customers with the aim to meet the expectations of establishing, developing and commercializing company-customer relationships; ultimately satisfying the interested parties (Omenugha, 2015; Korper \& Ellis, 2001). From a historical point of view, the first common case of digital marketing was conducted by a marketing worker of Digital Equipment Corporation (DEC); who on May $3^{\text {rd }} 1978$, sent out an email to some people in the US West Coast to promote a new model of DEC computer ('Online advertising', 2014 cited in Omenugha 2015a). Over the years, digital marketing has continued to improve and grow on various internet-enabled technologies and platforms such as smart mobile phones, laptops, web services, social networking sites and mobile apps. They are providing newer means to conducting daily activities; including media, business and marketing work. For instance, these technologies and platforms enable the application of special visual effects in brand content packaging and online placement. Moreover, digital marketing tools provide brands and businesses with the ability to develop newer skills that would enable them conduct marketing tasks and achieve set goals. For instance, the visual effects afford the opportunities for the brands and businesses to re-design, polish, add graphic designs and perform other creative tasks while developing communication content (Pavlik, 2001).

With global internet rise, digital marketing and promotional strategies appear to be on the increase and a common practice among brands and businesses; however, with various levels of penetration across different places in the world. Essentially, the rising status of internet and the attendant presence of new media technologies; including smart phones, have further brought a crucial modification in the way businesses presently utilize the conventional media like newspaper, radio and television to reach their customers. Great effort has been put into identifying, reaching, engaging and retaining customers through digital marketing platforms; including the social media. Ultimately, this novel arrangement presents brands, businesses and advertisers with the opportunity and new strategy to promote their products and services with an attendant effect on collaborating with customers and delivering purchase decisions through digital marketing and social media (Jobber and Ellis-Chadwick, 2013; Kaplan \& Haenlein, 2010). Digital devices (like smart mobile phones and digital TV); and promotional platforms (social media and search engine marketing) have become significant to everyday business life and exert a reasonable impact on customer's knowledge about products and services, as well as actions (Harris \& Rae, 2011; Grönroos, 2005).

\section{The Social Media Platform as a Digital Marketing and Promotional Strategy: An Overview Discourse}

Social media is basically just one of the platforms of digital marketing. Strictly connected with the Web 2.0, social media platform provides communication channels that bring users together for development of content, collaboration, exchange of ideas and information. Adweek (2018) noted that people tend to spend nearly 2 hours a day on social media platforms. Some of the popular social media platforms are: Facebook, Twitter, Instagram and YouTube. According to Kaplan \& Haenlein, (2010) the number of social media users in the world is rising daily, with progressively more people that feel the need to share their life moments, ideas or simply pass on information to the rest of the users. 


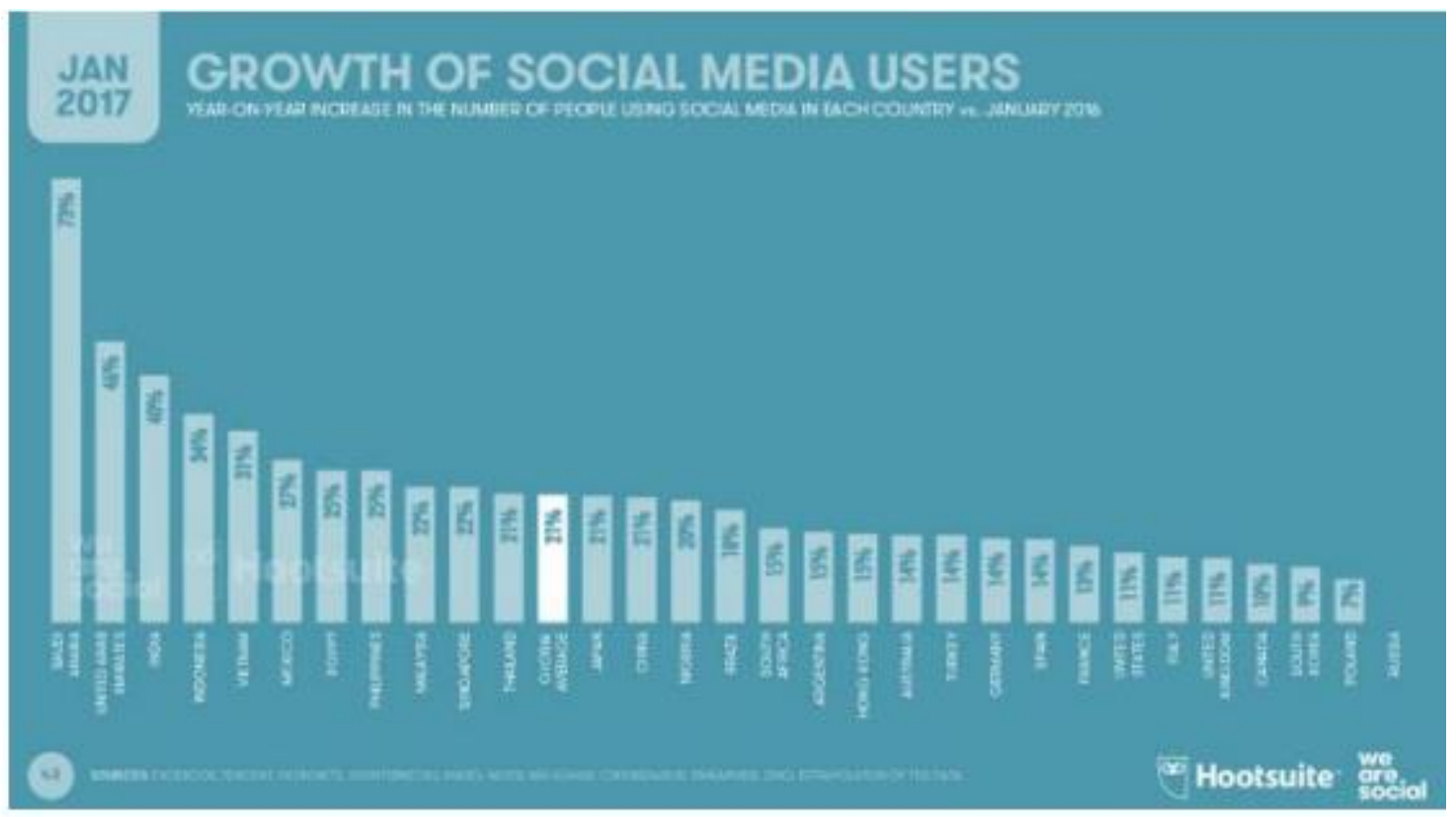

Figure 1. Growth of Social Media Users.

Source: Hootsuite.com.

As it does for individual users' lives, social media is continuously evolving and rapidly developing the business environment. In 2017, Statista attested that $81 \%$ of the US population (2.34 billion) actively use social media; suggesting that potential customers and targets are present across different social media platforms. Ultimately, from the point of view of business and corporate strategy, social media platforms have been recognized as an opportunity and potential channel for their digital marketing and promotional strategies. The social media platforms are democratized (Jaff, 2005); and allow both individual and commercial users to participate, in terms of content creation, content review, content communication, buying and selling; customer relationship management and many other business services (Gummesson, 2002; Grönroos, 1994). For any savvy business and marketer, this democratized nature alone would be enough reason to use social media marketing to reach and engage customers; potentially daily. More so, the social media platform is adjudged the most available cost-effective marketing channel with the capacity to demographically (age, gender, location) target customers.

In order to create an efficient and effective digital media marketing plan, brands and businesses are investing time and resources to understand and integrate different social media platform (Healey, 2014; Jaff, 2005). Termed social media marketing, brands are finding new customers, building followers and promoting their products and services through various social media channels. Essentially, social media marketing either come in free or for a fee (paid way) at point of use. The former has to do with reaching and building a fan base by sharing useful content, running contests and engaging customers online. The latter comes through as a paid advertisement; where a brand pays and uses, for instance Facebook ads, Twitter, Instagram, and YouTube to market its products and services. Compared with the former approach, the marketing content through paid advertising reaches a larger audience and more followers.

More so, critical to social media marketing is the capacity of the company or marketer to identify and combine suitable social media platforms to fit the set marketing objectives. Jobber and Ellis-Chadwick (2013) note that an effective social media marketing strategy is one which enables brands to recruit new customers; while retaining the already existing ones through customer relationship management (CRM), customer satisfaction and shielding against competition. Consequently, a strategic effort to identify, select and adapt fit-for-purpose social media platform is key to optimizing and achieving digital marketing objectives. According to Chaffey (2004, p.318), the three (3) approaches to attaining optimized social media marketing are:

a. Identifying how and which of the social media platforms can be used for marketing research to find out customers' needs and wants.

b. Anticipating the social media online revenue contribution. 
c. Recognizing the social media platform which can achieve customer satisfaction. Satisfaction here refers to the platform with convenient usability and adequate performance; with the ability to identify what the standard associated customer service is.

Below are the descriptions of the most relevant social media platforms commonly used by brands and businesses in digital marketing and promotion strategy:

\subsection{Facebook}

Launched in 2004 by Mark Zuckerberg, Facebook, which was initially limited to the Harvard University students, was opened to everyone in 2006. Today, with 2.1 billion active users, it has established itself as the first global social media platform (Zephoria Digital Marketing, 2017; Zuani, 2017). Facebook users are enabled to create a personal profile; develop, publish, review and share other users' content like text, photo and video. From a business perspective, Facebook provides opportunity for businesses and brands to generate awareness about their products and services; including posting content, generating response, offering feedback and establishing direct relationships with their customers.

\subsection{Twitter}

Twitter social network was created by the Obvious Corporation (San Francisco) and allows users to post text messages, though with a limited length (140 characters), called "tweets". The platform introduces the hashtags which allow a sort of grouping by putting together messages with the same tag. Users have a profile and are able to follow other users' profiles. In business, twitter allows brands to communicate content to their followers; and followers can make positive or negative comments about them. However, as the characters in the "tweets" are limited, businesses cannot receive detailed feedback from their customers in the platform.

\subsection{Instagram}

Founded by Kevin Systrom and Mike Krieger in October 2010, Instagram enables users to share videos and photos with captions and hashtags; review other users' photos as well as send direct messages to them. With over 700 million users (Aslam, 2017 cited in Zuani, 2017), Instagram presents a veritable platform for brands that want to display its products to a large amount of people. As the platform is popular and driven by post of photos and videos, businesses are able to let their customer see their finished product through the production processes.

\subsection{YouTube}

YouTube is a social website that allows users to upload, view and comment on videos. There are currently 1.5 billion YouTube users (Matney, 2017 cited in Zuani, 2017). Brands can use the platform to show and explain their complex products and services to their customers. Marketing messages can also be published and featured on the platform to target users and ultimately elicit purchase decisions.

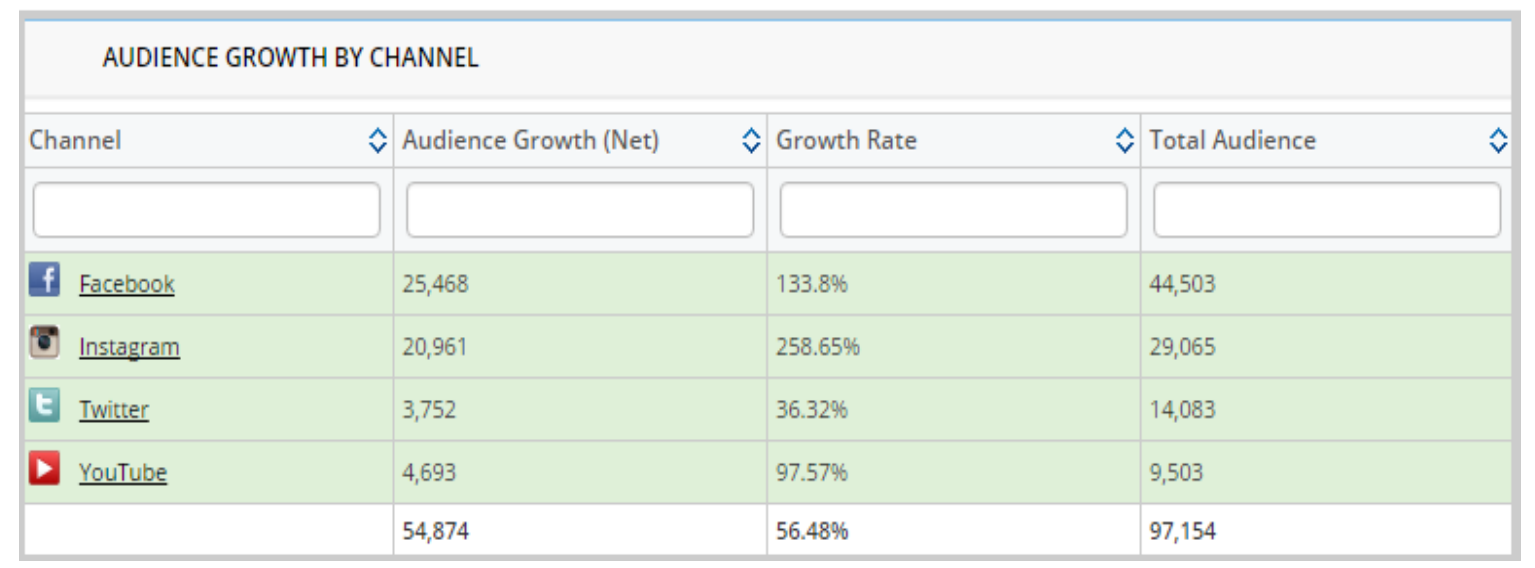

Figure 2. Audience Growth by Channel (Facebook, Instagram, Twitter and YouTube).

Source: Lyfemarketing.com.

Roesler Peter (2013) has identified four factors that reasonably affect the social media marketing as time and date; personality, call to action and post type.

a. Time and date: Time of the day has been identified as an influence on how people respond to certain content uploaded on the social media platform. Even though the social media platforms are online 24 hours of the day, there are different traffic patterns for each of those platforms; consequently affecting the way consumers respond to messages 
(Chaffey, 2011). For instance, Roesler (2013) notes that traffic for most platforms, like Facebook and Twitter builds after 9 a.m. and begins to dwindle after 4 p.m. LinkedIn, with its focus on professional networking, has less traffic during business hours when most of its users are at the workplace. Hence, brands must identify and recognize the timing and traffic schedule for each of the social media platforms to be able to properly target and reach users.

b. Personality: The content of social media is expected to have a consistent tone and voice which the users can relate to and are eager to interact with. Brands must therefore be able to develop a tone and personality that fit their image (Roesler, 2013). A mismatch between brand tone and personality can ultimately lead to disconnection between users and brands. For instance, brands that focus on younger users would want to be more light-hearted and wittier than brands with an older audience which would want to remain professional and serious.

c. Call to Action: Absence of call to action affects the flow of engagement between brands and customers; consequently affecting social media marketing. Brands and marketers need to be proactive to have a call to action of their posts; such as asking questions, seeking suggestions and requesting sharing (Roesler, 2013). This is one way to interact and engage customers (Chaffey, 2011).

d. Post Type: While different social media platforms allow for several posts, some content encourages more engagement than others. Adweek noted that photos and videos are the most engaging type of posts; text status updates are the next most engaging; and links are the least engaging. However, this does not apply for all platforms (Roesler, 2013). Brands must have proper knowledge of their customers; including identifying and recognizing the social media platforms that their customers use and what kind of content that could effortlessly engage them.

Ultimately, brands and marketers need to vigilantly and creatively review the progress of their social media marketing and promotional strategies, and research what they can do to optimize their efforts. Moreover, brands and marketers require a new set of skills to cope with the increasingly competitive market. Among others, these skills are combined and manage to help create and introduce digital effects in content development; allowing brand to appeal, engage and interact with the target. Brands abandon their social media marketing efforts prematurely because they do have the right set skills to achieve marketing goals which they have set and thus; feel it is too difficult to comprehend social media platforms.

\section{Social Media Marketing: A Case of Taliah Beauty Product}

This section offers background information on the activities of the Taliah beauty product. It also examines the social media marketing strategy of the brand; reviewing the different social media platforms relied upon to launch and promote itself in the market. Interpretations of insights were made to offer understanding into what the brand had achieved from adopting social media marketing as a promotional strategy. Social network theory provided the apt theoretical prism to position and explain the effects of social media marketing strategy.

\subsection{About Taliah Beauty Product}

Taliah is an African American adjudged organic and beauty brand. Founded by Taliah Waajid, at age 14, the brand has evolved and grown for over 25 years; leading the way in innovation and education for natural hair, health and beauty. Customer engagement is at the heart of the brand activities. Taliah's journey in the natural hair and health products has taken her through seminars, trainings and exhibitions where she engaged her targets to educate them on the organic and chemical-free nature of the brand. Remarkably, the brand has gone from ' 25 exhibitors and 150 attendees (when Taliah Waajid first started attending the World Natural Hair, Health \& Beauty Show ${ }^{\mathrm{TM}}$ ), to over 200 exhibitors and 40,000 attendees from around the world' (naturalhair.org/taliah-waajid). However, the brand needed to do more in terms of reach of users for engagement, education and traffic-drive as that cannot be achieved by interpersonal communication; including face-to-face marketing. There was need to engage and educate a larger audience as well as cost-effectively drive traffic to the brand. These inspired the Natural Hair Care specialist and licensed Master cosmetologist, Taliah to launch her beauty brand on different social media platforms; predominately Facebook, Twitter, Instagram and YouTube.

\subsection{Taliah's Social Media Promotional Platforms}

Facebook, Twitter, Instagram and YouTube are the major identified social media platforms utilized by Taliah as strategic promotional tools. Particularly, the brand promotes its online presence as well as identifies and engages (including generating reviews and feedback) the customers at a very low cost. Lyfemarketing.com reported that between October 1, 2015 to 31st August, 2016, (10 months interval) Taliah's social media management generated below users' feedback and impression: 
Table 1. Social media platform and generated impression. Source: Lyfemarketing.com.

\begin{tabular}{l|l|l}
\hline $\mathrm{S} / \mathrm{N}$ & Social Media Platform & Impression \\
\hline 1 & Facebook & $\begin{array}{l}1.25,468 \text { Facebook Fans } \\
2 . \$ 0.16 \text { per Facebook Fan }\end{array}$ \\
\hline 2 & Instagram & 20,961 Instagram Followers \\
\hline 3 & Twitter & 3,752 Twitter Followers \\
\hline 4 & YouTube & 4,693 YouTube Subscribers \\
\hline Total Engagements & 263,052 \\
\hline Cost per Engagement & $\$ 0.004$ \\
\hline Video views & 146,585 \\
\hline Cost per view & $\$ .01$ \\
\hline
\end{tabular}

The report asserted that the Taliah brand engaged exact target customers for as little as $\$ 1$ and less than 0.20 cents on average (Cost per fan + cost per engagement + cost per view).

Here's a screenshot from their ads manager showing 0.16 per fan.

\begin{tabular}{|c|c|c|c|c|c|}
\hline Campaign Name & Deilvery 0 & Results 0 & Reach 0 & Cost per Result 0 & Amount Spent 0 \\
\hline Talah - Pase Lhes - LVFE & - Deleted & $\begin{array}{r}20.217 \\
P a p e t\end{array}$ & 302.330 & $\begin{array}{r}50.16 \\
\text { Per Page L L the }\end{array}$ & $53,235,73$ of 53,23577 \\
\hline
\end{tabular}

Here's a look at the $\$ .01$ cost per view.

\begin{tabular}{|c|c|c|c|}
\hline Results 0 & Reach 0 & Cost per Res... 0 & Amount Spent 0 \\
\hline $\begin{array}{l}93.261 \\
\text { 3.Second Viseo V }\end{array}$ & 156,383 & $\begin{aligned} & 50.01 \\
& \text { Per 3-Second Vide }\end{aligned}$ & $\$ 740.17$ \\
\hline
\end{tabular}

(The cost per view is a lot more effective and cost efficient than traditional TV network advertising).

Here's a look at the \$.004 engagement cost.

\begin{tabular}{|r|r|r|}
\hline 31.023 & 62.902 & 50.01 \\
\hline Post Engogements & & Per Post Engogem \\
\hline
\end{tabular}

Here are some of the posts with engagement:

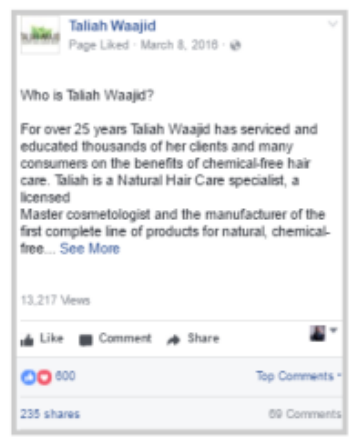

Figure 3. Post and Engagement (a).

Source: Lyfemarketing.com 


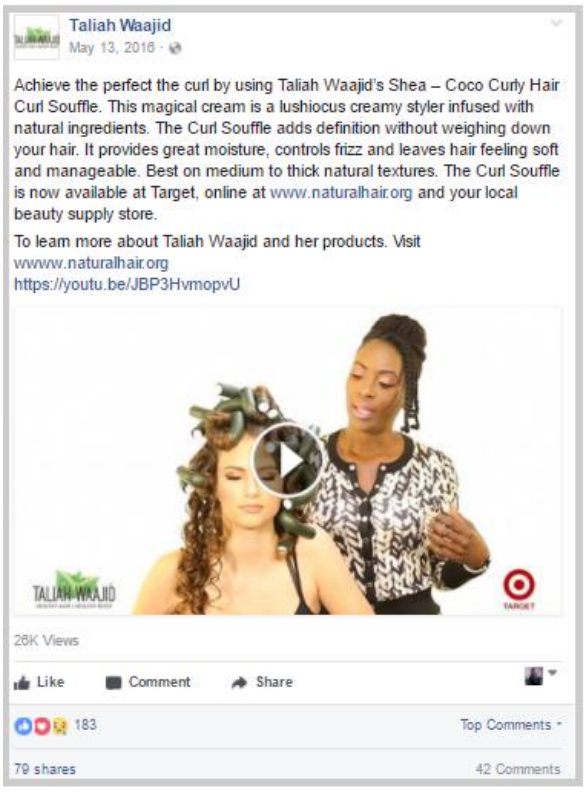

Figure 4. Post and Engagement (b).

Source: Lyfemarketing.com

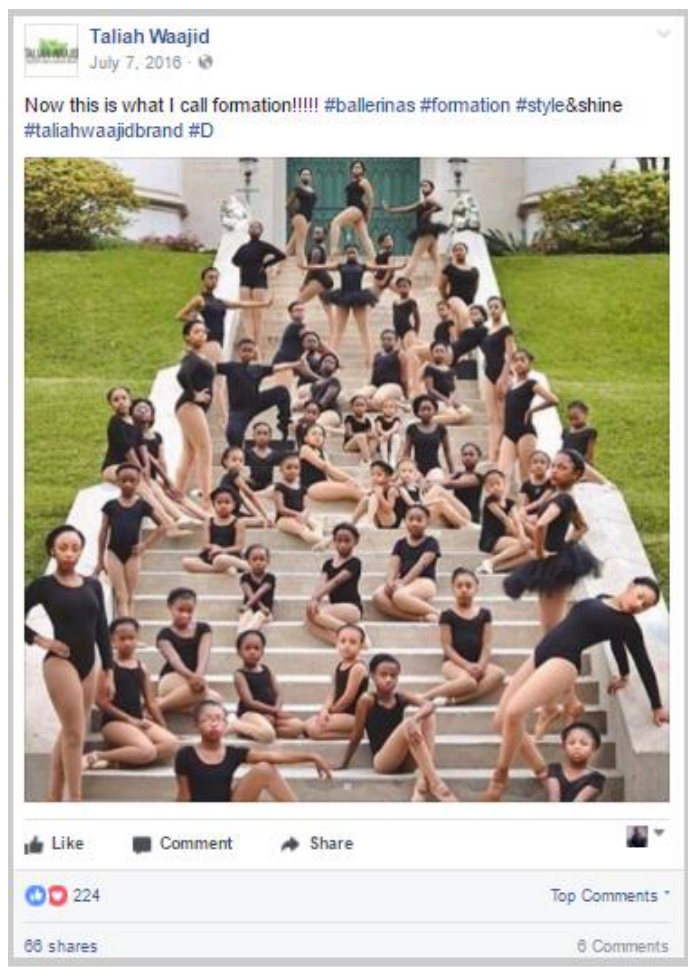

Figure 5. Post and Engagement (c).

Source: Lyfemarketing.com 
Here is a review that their brand manager left for us:

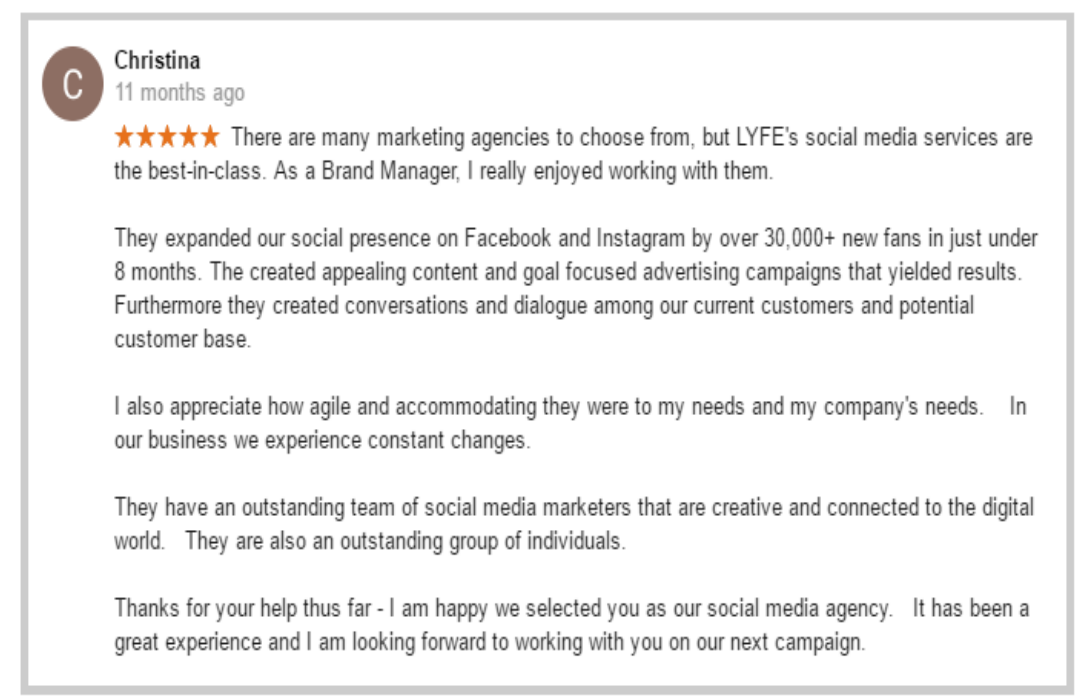

Figure 6. Brand Manger review

Source: Lyfemarketing.com

\subsection{An Overview Discourse of Taliah's Social Media Management}

The above background information on Taliah and its marketing efforts - offline and online attempts to present and compare marketing successes in both platforms.

In terms of reach and engagement, it could be seen that the Taliah brand had captured more users and customers on the social media platforms $(263,052)$ when compared to the offline interpersonal marketing effort of attending exhibitions $(40,000)$. Moreover, it brought convenience to the brand management team as they would no longer need to be physically present at every exhibition, seminar and training to engage with the customers and educate the users.

The presence of the brand on different social media platforms (particularly, Facebook, Instagram, Twitter and YouTube) enables at a click of button; to identify and target different demographic components of the audiences at different locations; capturing prospects' attention and building relationships which are essential to social media marketing and promotion management (Jobber and Ellis-Chadwick, 2013; Chaffey, 2011; Kaplan \& Haenlein, 2010).

The feedback seen to be generated from these platforms offered insight and helped Taliah to understand the concerns and views of its users; ultimately adapting them to improve quality of products and services. Moreover, as competition emerges in the business, the social media platforms would serve as veritable platform for building of trust and reliability between brands and customers (Chaffey, 2004; Korper \& Ellis, 2001). For instance, the screenshot above (figure 4) saw Taliah's social media marketing effort in establishing its brand as a leading one in the natural hair, health and beauty industry. Video was posted to demonstrate to the users and target customers how the product was being used. This provided real-time knowledge on the applicability of the product; engaging users to understand and connect to the activities of the brand.

Through frequent educational updates and information, Taliah was able to present itself as a competitive and reliable destination that users can always visit to gain insight into health and beauty lifestyle. In addition, the combination, use and management of several social media platforms (Facebook, Instagram, Twitter and YouTube) had ensure the brand reach and engage a large diverse conglomerate of people to attain some level of broadness.

\subsection{Theoretical Positioning}

The emergence and application of social media to digital marketing practice creates changes, provides innovation as well as the capacity positions for businesses and brands to attain new position in the market. Moreover, the new digital market system introduces new tasks such as researching, information monitoring and data mining to the marketing and promotional practice. This presents benefits to emerging and established brands and businesses; particularly in conveniently, simultaneously and timely creating, disseminating and managing brand information. In this way, brands and businesses are able to customize a heterogeneous network efficiently while transporting media content across different social media platforms. 
Therefore, Social network theory provides an appropriate framework to better position, discuss and understand social media marketing activities and promotional strategies. The basic notion of social network theory is that people tend to think and behave similarly because they are socially connected (Miles, 2012). It focuses on the interactions among network members and the structure of those interactions. Through these online interactions and consumption of online links; including membership to social media platforms, social ties are created. However, these ties may be weak or strong, open or closed, directional or reciprocal (Richardson, Choong \& Parker, 2016); depending on the capacity of an idea to interact, engage and generate emotional connection among participants. As customer satisfaction is at the heart of marketing (Omenugha, 2018), brands are expected to creatively engage, recruit and retain customers against the backdrop of competition. This is achieved by social interaction which provides opportunities to establish strong and close ties with customers who could reciprocate the connection. Social media platforms deliver prospects for social networking as brands can utilize the platforms to engage in value creation as well as efficiently and effectively collaborate with customers to foster brand communities (Andersen, 2005). This is what Taliah beauty product intends to achieve by adopting diverse social media platforms to engage, educate and drive customers' traffic to its brand.

\section{Conclusion}

This overview review discourse shows that there is a great effort being made by brands to identify, reach, engage and ultimately retain customers through digital marketing platforms and promotional strategies. The social media platform is one of the veritable platforms increasingly relied on by brands and businesses to achieve these marketing objectives. This was largely as a result of the interactivity, cost-effectiveness and the capacity of the social media platforms to target and reach customers irrespective of location, social and demographic orientation. However, factors such as time and date; personality, call to action and post type affect the full optimization of social media marketing. A review of the social media marketing strategy of Taliah beauty product shows that the brand had done well and achieved greater impact (in reach and engagement of users) through the social media platforms (predominately Facebook, Twitter, Instagram and YouTube) when compared to the offline interpersonal marketing strategy (attending exhibitions and fairs). The paper was situated within the social network theoretical framework which helps to show that Taliah's social media marketing objective was essentially to stimulate social interaction and build emotional ties with users. This interaction provided the platform for the brand to engage and educate target users about organic, natural and chemical-free hair, health and beauty.

\section{References}

'Adweek.com' (2018).

Andersen, P. H. (2005). Relationship marketing and brand involvement of professionals through web enhanced brand communities: the case of Coloplast. Industrial Marketing Management, 34(1), 39-51. https://doi.org/10.1016/j.indmarman.2004.07.002

Chaffey, D. (2004). E-Business and E-Commerce Management ( $2^{\text {nd }}$ edn), England: Pearson Education ltd.

Chaffey, D. (2011). E-Business and E-Commerce Management (5 $5^{\text {th }}$ edn), England: Pearson Education ltd.

Gummesson, E. (2002). Total Relationship Marketing, Marketing Management, relationship strategy and CRM Approaches for the Network Economy, $\left(2^{\text {nd }}\right.$ edn). Butterworth-Heinemann publications.

Grönroos, C. (1994). From Marketing Mix to Relationship Marketing: Towards a Paradigm Shift in Marketing, Management Decision, 32(2), 4 - 20. https://doi.org/10.1108/00251749410054774

Grönroos, C. (2005). Service management and Marketing- A customer relationship management approach.

Harris, L., \& Rae, A. (2011). Building a personal brand through social networking, Journal of Business Strategy. https://doi.org/10.1108/02756661111165435

Healey, M. (2014). What is Branding? https://gjfcol.wordpress.com/2014/12/30/what-is-branding-by-matthew-healy/

Hootsuite. (2017). 'We are social'.

Jaff, J. (2005). Life After The 30-Second spot; Energize your Brand with a Bold Mix of alternatives to Traditional Advertising.

Jansen, J. B., \& Schuter, S. (2011). Bidding on the buying funnel for sponsored search keyword advertising, Journal of Electronic commerce Research, 12(1).

Jobber, D., \& Ellis-Chadwick, F. (2013). Principles and Practice of Marketing, ( $7^{\text {th }}$ edn), Berkshire, McGraw-Hill Education.

Kaplan, A. M., \& Haenlein, M. (2010). Users of the world, unite! The challenges and opportunities of social media, 53, 59-68. 
Korper, S., \& Ellis, J. (2001). The E-commerce Book: Building the e-empire, San Diego: Academic Press.

Laudon, K. C., \& Traver, C. G. (2012). E-commerce ( $8^{\text {th }}$ revised edn), Boston: Prentice Hall.

Lyfemarketing.com, (n.d), '3 successful social media management campaigns (Case Study)', Retrieved from https://www.lyfemarketing.com/social-media-management-case-study/

Miles, J. A. (2012). Management and Organization theory, CA: Jossey-Bass.

'Naturalhair.org/taliah-waajid' (2018).

Omenugha, N. O. (2015). Communicating contents among Nigerian Telecommunication Service Providers: How has face-to-face Media fared? International Journal of Arts \& Sciences, 08(08), 551-562.

Omenugha, N. O. (2015a). The Influence of Online Marketing on Customer Behaviour in Nigeria, Retrieved from https://www.researchgate.net/publication/320565163_THE_INFLUENCE_OF_ONLINE_MARKETING_ON_CU STOMER_BEHAVIOUR_IN_NIGERIA

Omenugha, N. O. (2018). The utilization of digital platforms for marketing in the Nigerian entertainment and media (E\&M) industry: prospects and challenges, Case Studies in Business and Management (E-ISSN 2333-3324), (June issue), 5(1), 60 - 79.

Pavlik, J. V. (2001). Journalism and new media. Columbia University Press. https://doi.org/10.7312/pavl11482

Richardson, P., Choong, P., \& Parker, M. (2016). Social Media Marketing Strategy: Theory and Research Propositions, Journal of Marketing Development and Competitiveness, 10(2).

Roesler, P. (2013). Four Factors That Affect Social Media Marketing Performance, Retrieved from https://www.webmarketingpros.com/blog/four-factors-that-affect-social-media-marketing-performance/

Zeforia.com. (2017). 'The top 20 valuable Facebook statistics'.

Zuani, A. (2017). Digital Marketing in China: An Analysis of the social media strategy of Tod's Group (Masters Dissertation), Universita Ca Foscari Venezia.

\section{Copyrights}

Copyright for this article is retained by the author(s), with first publication rights granted to the journal.

This is an open-access article distributed under the terms and conditions of the Creative Commons Attribution license which permits unrestricted use, distribution, and reproduction in any medium, provided the original work is properly cited. 